0406 PROSPECTIVE MONITORING OF EXPOSURE AND LUNG FUNCTION AMONG CEMENT PRODUCTION WORKERS IS DROP OUT FROM THE STUDY ASSOCIATED WITH RESPIRATORY HEALTH AT INCLUSION?

Karl-Christian Nordby, Hilde Notø, Wijnand Eduard, Marit Skogstad, Helge Kjuus. National Institute of Occupational Health, Oslo, Norway

\subsection{6/oemed-2014-102362.160}

Objectives In this study we aimed to estimate the associations between respiratory health at inclusion and drop-out from a 4year longitudinal study of lung function among cement production workers in Europe and Turkey.

Method Non-administration workers $(\mathrm{n}=3203)$ aged 17-54 yrs in 22 cement production plants in eight countries were included. Geometric mean (GM) exposure to the thoracic fraction of the workplace aerosol was allocated individually by job type and plant from a database of 6111 measurements from the follow-up study. Drop out was analysed in logistic regression with year of hire, exposure level, airway symptoms, chronic obstructive pulmonary disease (COPD) and use of airway protection at inclusion as explanatory variables. COPD was defined as $\mathrm{FEV}_{1} / \mathrm{FVC}<0.7$.

Results COPD at inclusion was associated with drop out, but only among those hired 6-10 years before inclusion (OR 2.4 [CI $95 \% 1.1-5.5])$. GM exposure exceeding a level of $1.61 \mathrm{mg} / \mathrm{m}^{3}$ was associated with drop out $(\mathrm{OR}=1.9$; CI 95\% 1.3-2.7) compared to exposure below $0.42 \mathrm{mg} / \mathrm{m}^{3}$. The use of respiratory protection at inclusion was inversely associated with drop out (OR 0.6 [CI 95\% 0.4-0.9]). Age, sex, allergy, asthma and previous occupational exposure to dust and gases did not confound the associations.

Conclusions Workers in the highest exposed group had increased risk, while those who reported using a respiratory mask had reduced risk of dropping out. Participants classified with COPD at inclusion were to some extent depleted from the study, but only among those hired 6-10 years before their inclusion.

\section{SEPARATING WITHIN- AND BETWEEN-GROUP EXPOSURE EFFECTS IN A PANEL STUDY ON PESTICIDE USE AND EARLY BIOLOGICAL EFFECTS IN THE CORN FARMERS STUDY}

${ }^{1}$ Lützen Portengen, ${ }^{2}$ Anneclaire J De Roos, ${ }^{3}$ Laura Beane Freeman, ${ }^{1,4}$ Roel Vermeulen. ${ }^{1}$ Institute for Risk Assessment Sciences, Utrecht University, Utrecht, The Netherlands; ${ }^{2}$ Department of Environmental and Occupational Health, School of Public Health, Drexel University, Philadelphia, PA, USA; ${ }^{3}$ Occupational and Environmental Epidemiology Branch, Division of Cancer Epidemiology and Genetics, National Cancer Institute, Rockville, MD, USA; ${ }^{4}$ Julius Center, Utrecht Medical Center, Utrecht, The Netherlands

\subsection{6/oemed-2014-102362.161}

Objectives We aimed to estimate the effect of pesticides on selected early biological effects among farmers, allowing for different effects of within-person and between-group (unexposed controls versus farmers) changes over time. Using a group-level estimate of exposure is a well-known approach to reduce impact of measurement error on estimated exposure-response relations. With only few exposure groups this results in an ecological study design, with potential for "aggregation" bias. By group-mean centering of individually assigned exposures it is possible to separately estimate within-individual and between-group exposure effects
Method Pesticide exposure information, blood and urine were collected throughout a growing season from male corn farmers $(\mathrm{n}=30)$, and non-farming controls $(\mathrm{n}=10)$. We used a hierarchical mixed model to relate change in cumulative exposure to atrazine and 2.4-D from before to during the spraying season to plasma levels of 22 immuno-modulatory cytokines and compared this to a more conventional model using individual exposures only.

Results Model fit for group-mean centred models averaged better than for non-centred models (lower AICs for 20/22 models for atrazine and 18/22 models for 2.4-D). Estimates for between-group differences in exposure were very similar to those from conventional (non-centred) models, while standard errors for estimates based on within-individual differences were relatively large $(5 \mathrm{x}$ those for estimates based on between-group differences).

Conclusions Group-mean centering of exposures allowed us to estimate and contrast exposure-response relations based on differences between groups and within individuals. Comparison with a more conventional approach, ignoring the clustering of individuals, showed that effect estimates were dominated by differences between groups.

\section{THE MANAGEMENT OF PATIENT/VISITOR (TYPE II) VIOLENCE BY THE HOSPITAL UNIT NURSE MANAGERS AND STAFF}

${ }^{1}$ Lisa Pompeii, ${ }^{2}$ Ashley Schoenfisch, ${ }^{2}$ Hester Lipscomb, ${ }^{2}$ John Dement, ${ }^{1}$ Mudita Upadhyaya. ${ }^{1}$ The University of Texas, Houston, Texas, USA; ${ }^{2}$ Duke University Medical Center, Durham, NC, USA

\subsection{6/oemed-2014-102362.162}

Objectives To examine the management of workplace violent events (type II) by hospital unit nurse managers and staff.

Method Cross-sectional surveys, telephone interviews, and semistructured focus groups were employed among nurse managers and nursing unit staff in two large hospital systems.

Results Nurse managers and staff perceived an increase in type II violence in recent years which they attributed to an increase in financial needs of patients/families, and drug seeking behaviour. Both groups expressed sometimes feeling unsupported by their institutions with regard to their safety in the context of these events due to their organisation's focus on maximising patient/visitor satisfaction, poorly defined/enforced visitor policies, and movement away from physical/chemical patient restraints. Nurse managers perceived themselves as the designated person on their unit responsible for de-escalation of violent situations, with security called only in extreme situations. Security involvement was not consistently considered an option for managing violent events. Unit staff concurred that they relied on their managers to assist, but were left to handle this in their absence. Managers expressed feeling torn between having to consider patient satisfaction versus worker safety at times. They sometimes resorted to rotating patients, known to be violent, between hospital units for purposes of relieving staff from overexposure to violent behaviour.

Conclusions Poorly defined and/or enforced hospital level policies results in nurse managers and staff being left to determine how violent events are managed, which sometimes occurs at the expense of their safety. Efforts at identifying effective institutional and unit level violence prevention policies and stategies are needed. 